AperTO - Archivio Istituzionale Open Access dell'Università di Torino

\begin{abstract}
Alternative monotherapy or add-on therapy in patients with epilepsy whose seizures do not respond to the first monotherapy: an Italian multicenter prospective observational study.
\end{abstract}

This is a pre print version of the following article:

Original Citation:

Availability:

This version is available http://hdl.handle.net/2318/158088

since

Published version:

DOI:10.1016/j.yebeh.2013.05.038

Terms of use:

Open Access

Anyone can freely access the full text of works made available as "Open Access". Works made available under a Creative Commons license can be used according to the terms and conditions of said license. Use of all other works requires consent of the right holder (author or publisher) if not exempted from copyright protection by the applicable law. 
Provided for non-commercial research and education use. Not for reproduction, distribution or commercial use.

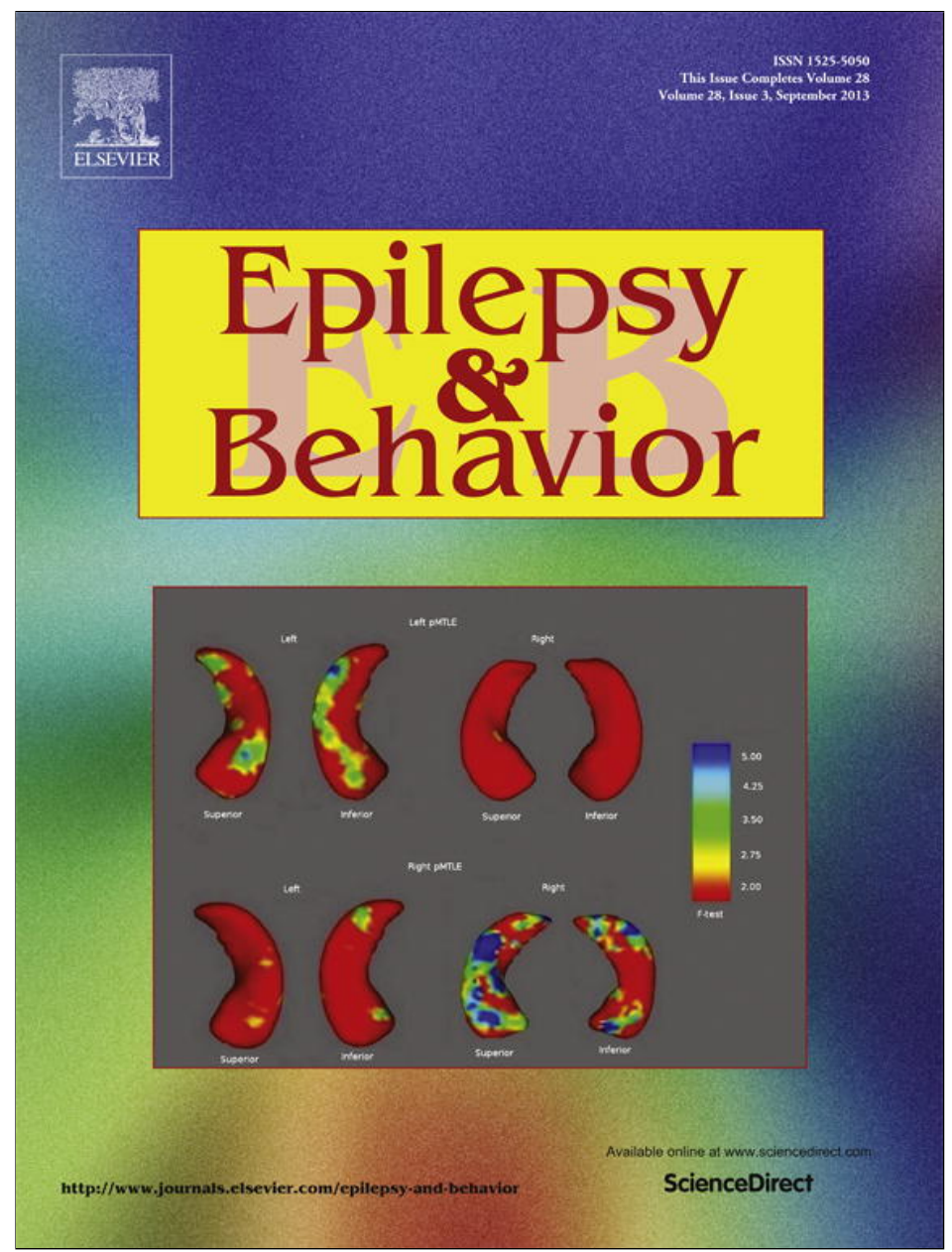

This article appeared in a journal published by Elsevier. The attached copy is furnished to the author for internal non-commercial research and education use, including for instruction at the authors institution and sharing with colleagues.

Other uses, including reproduction and distribution, or selling or licensing copies, or posting to personal, institutional or third party websites are prohibited.

In most cases authors are permitted to post their version of the article (e.g. in Word or Tex form) to their personal website or institutional repository. Authors requiring further information regarding Elsevier's archiving and manuscript policies are encouraged to visit:

http://www.elsevier.com/authorsrights 


\title{
Alternative monotherapy or add-on therapy in patients with epilepsy whose seizures do not respond to the first monotherapy: An Italian multicenter prospective observational study ${ }^{2}$
}

\author{
Andrea Millul ${ }^{\mathrm{a}}$, Alfonso Iudice ${ }^{\mathrm{b}}$, Marina Adami ${ }^{\mathrm{c}}$, Roberto Porzio ${ }^{\mathrm{c}}$, Flavia Mattana ${ }^{\mathrm{a}}$, \\ Ettore Beghi $^{\text {a,* }}$, The THEOREM Study Group ${ }^{1}$
}

a Laboratorio di Malattie Neurologiche, IRCCS, Istituto Mario Negri di Milano, Italy

${ }^{\mathrm{b}}$ Dipartimento di Neuroscienze, Università di Pisa, Italy

c Janssen-Cilag SpA, Medical Affairs, Cologno Monzese, Milan, Italy

\section{A R T I C L E I N F O}

\section{Article history:}

Received 18 April 2013

Revised 10 May 2013

Accepted 31 May 2013

Available online 26 July 2013

\section{Keywords:}

Monotherapy

Polytherapy

Cohort study

Epilepsy

\begin{abstract}
A B S T R A C T
A prospective multicenter observational study was undertaken on children and adults with epilepsy in whom first monotherapy failed, to assess indications and effects of alternative monotherapy vs. polytherapy. Patients were followed until 12-month remission, drug withdrawal, or up to 18 months. Monotherapy and polytherapy were compared for patients' baseline features, indication, retention time, remission, adverse events (AE), quality of life, and direct and indirect costs. Included were 157 men and 174 women, aged 2-86 years. Of the patients, $72.2 \%$ were switched to alternative monotherapy. Baseline treatment was changed for lack of efficacy (73.9\%) or adverse events (26.1\%). Two hundred forty-three completed the study (remission: 175; 72.0\%). Retention time, hospital admissions, days off-work and off-school, and quality of life did not differ between the two treatment groups. Patients were followed for 365.3 person-years. Three hundred eighty-three incident AEs were reported by $46.4 \%$ of patients in monotherapy and $40.2 \%$ in polytherapy (serious AEs: $9.6 \%$ vs. $8.7 \%$, mostly nondrug-related).
\end{abstract}

(c) 2013 Elsevier Inc. All rights reserved.

\footnotetext{
is Alternative monotherapy versus polytherapy.

* Corresponding author at: Laboratory of Neurological Disorders, IRCCS, “Mario Negri” Institute, Via G. la Masa 19, 20156 Milan, Italy. Fax: + 390239001916.

E-mail addresses: andrea.millul@marionegri.it (A. Millul), a.iudice@neuro.med.unipi.it (A. Iudice), madami@its.jnj.com (M. Adami), rporzio@its.jnj.com (R. Porzio), flavia.mattana@phideamarvin.com (F. Mattana), ettore.beghi@marionegri.it (E. Beghi).

${ }^{1}$ Members of the THEOREM Study Group include Umberto Aguglia, Edoardo Ferlazzo, Vittoria Cianci, Sara Gasparini (Catanzaro e Reggio Calabria); Paolo Aloisi, Alfonso Marrelli, Claudio Martinazzo, Claudio Porto, Catia Capannolo (L'Aquila); Luisa Antonini, Giovanni De Maria, Bruno Guarneri (Brescia); Giovanni Asteggiano, Marina Patrini (Alba, CN); Paolo Balestri, Salvatore Grosso, Rosaria Pianigiani (Siena); Paola Banfi, Elena Guaschino (Varese); Pietro Bassi, Lorena Brunati, Giuliano Orsini (Milano); Graziella Bogliun, Lucia Azteni, Claudio Ruffmann (Monza); Rosella Bellomo, Stefano Zoccolella (Bari); Paolo Benna, Rossella Colonna, Mara Rosso, Elisa Montalenti (Torino); Dante Besana, Paolo Rasmini, Maurizio Cremonte, Ilaria Maraucci, Fabiana Vercellino (Alessandria); Roberto Biondi, Rosaria Verniccio, Giuseppina Vitale, Vito Sofia, Francesca Mazziotta, Maria Proietto (Catania); Giuseppe Bongiovanni, Paolo Borelli (Verona); Clementina Boniver, Marilena Vecchi, Lara Gallo (Padova); Edo Bottacchi, Lorenzo Maria Carenini (Aosta); Placido. Bramanti, Patrizia Pollicino (Messina); Carlo Buffa, Daniela Cassano, Daniele Imperiale (Torino); Salvatore Buono (Napoli); Roberto Campostrini, Paolo Forleo, Pasquale Palumbo (Prato); Giorgio Capizzi, Giovanni Rivalta, Maria Pieri, Roberta Vittorini (Torino); Cesare Cardinali, Nelia Zamponi, Elisabetta Cesaroni (Ancona); Susanna Casellato, Agnese Murgia (Sassari); Antonino Chindemi, Lorenzo Piscitelli (Acquaviva, BA); Paolo Curatolo, Caterina Cerminara, Roberta Bombardieri, Mariangela Pinci (Roma); Francesca Darra, Elena Fontana (Verona); Elvio Della Giustina, Gilda Caricati, Gianna Bertani, Carlo Fusco, Angela Scarano (Reggio Emilia); Ornella Daniele, Lidia Urso (Palermo); Alessandra Ferrari (Savona); Raffaele Ferri, Mariangela Tripodi (Troina, EN); Maurizio Fracassi (Genova); Emilio Franzoni, Sarajlija. Jasenka, Caterina Garone, Ilaria Cecconi, Valentina Marchiani, Grazia Salerno (Bologna); Dante Galeone, Vittorio Siruicchio, Pasquale Conti (Bari); Antonio Gambardella, Eleonora Colosimo, Ugo Leggio, Angelo Labate, Roberta Ambrosio (Catanzaro); Anna Teresa. Giallonardo, Jinane Fattuch, Carlo Di Bonaventura (Roma); Tiziana Granata, Francesca Ragona, Elena Freri, Laure Obino (Milano); Rosario Granato (Aversa, CE); Azzurra Guerra, Tiziana Giuva, Augusto Rizzo (Modena); Francesco Habetswallner (Napoli); Patrizia Maritato, Cinzia Lucchesi (Pisa); Diego Mansi, Luigi Serino(Napoli); Maria Giovanna Marrosu, Mariangela Vacca (Cagliari); Andrea Martinuzzi, Alexandra Liava (Conegliano Veneto, TV); Marta Maschio, Alessia Zarabla, Loredana Dinapoli (Roma); Massimo Mastrangelo, Barbara Scelsa, Isabella Fiocchi, Maria Stefania Bova, Chiara Oppezzo (Milano); Stefano Meletti, Giovanna Calandra (Modena); Fabrizio Monti, Luca Zanet, Marco Simonetto, David Strokely (Trieste); Giancarlo Muscas, Eleonora Rosati, Barbara Chiocchetti (Firenze); Marco Onofrj, Astrid Thomas, Anna Lisa Luciano, Francesca Anzellotti, Anna D'Andeagiovanni (Pescara); Francesco Paladin, Filippo Dainese, Federico Mainardi (Venezia); Paolo Piccinelli, Giovanni Pitillo, Matteo Ferri, Alexia Aldini, Silvia Perna, Maria Colombo (Varese); Pier Paolo Quarato, Addolorata Mascia, Giancarlo Di Gennario, Antonio Sparano (Pozzilli, IS); Emilio Ubiali,Stefano Quadri, Giuseppina Chiodelli (Bergamo); Francesca Vanadia, Daniela Buffa, Giuseppe Santangelo, Flavia Consolo, Santina Bona (Palermo); Giampaolo Vatti, Raffaele Rocchi(Siena); Alberto Verrotti, Daniela Trotta, Rossella Manco (Chieti); Antonio Vetro (Agrigento); Davide Zarcone, Annalisa Pozzi (Gallarate, VA).
} 


\section{Introduction}

About $50-70 \%$ of patients with newly diagnosed epilepsy achieve complete seizure remission after starting antiepileptic drugs as monotherapy treatment [1-4]. For those who continue to have seizures, the physician has two options, an alternative monotherapy (substitution) or a combination therapy (add-on), which generally involves adding a second drug to the current monotherapy. As randomized trials $[5,6]$ did not provide evidence of which strategy should be preferred, clinical practice will presumably present various treatment patterns, as shown by a collaborative survey on prescribing strategies in Mediterranean countries [7] and a survey of expert opinions in the USA [8]. In this complex scenario, with few exceptions $[9,10]$, the utilization of "classical" and "new" antiepileptic drugs is poorly understood. In addition, the safety profile of several possible treatment schedules is practically unknown. Finally, there is little or no information on how the different treatment choices affect health-related quality of life (HRQOL) and selected economic indices, such as costs of epilepsy care and consumption of medical resources.

This prospective observational, noninterventional study was therefore designed to describe the treatment strategies after failure of the first monotherapy in children and adults with epilepsy and the factors that influence neurologists' decisions. The impact of the two options (alternative monotherapy and polytherapy) on seizure remission, HRQOL, and resource consumption in an Italian population with epilepsy in a "real-life" clinical setting is described.

\section{Material and methods}

This multicenter, pragmatic, prospective, observational (cohort) investigation was done in secondary and tertiary outpatient services in Italy. To be eligible for inclusion, each patient had to be two years of age or older, to have a diagnosis of epilepsy [11], to reside in the center's catchment area, to have seizures that failed to respond to the first monotherapy for epilepsy, to be compliant with the assigned treatment and with the study's instructions, and to sign written informed consent. Excluded were patients using experimental drugs, receiving two or more antiepileptic drugs (AEDs) concurrently or in sequence, or previously treated with AEDs for other clinical indications (e.g., pain relief or psychiatric disorders).

Failing monotherapy was defined as either seizure recurrence despite doses judged by the physician to be maximally tolerated and/or adverse events requiring treatment withdrawal.

Two patient cohorts were defined at entry: alternative monotherapy and add-on therapy. The alternative monotherapy cohort included patients switching to a different single AED among those approved for monotherapy, and the add-on therapy cohort included patients in whom a second AED was added to their current monotherapy. The local investigators were instructed to include all eligible patients deserving treatment change at any time after a breakthrough seizure, a report of adverse drug reactions, or any other reason, depending on the clinician's decision. All conventional and locally approved newer AEDs could be prescribed, according to their label. As there was no prejudice for or against one of the two treatment strategies, we decided not to influence the caring physician's choice at any time during the study. Guidelines for treatment change were not imparted because they were against our purpose to examine treatment decisions as they were taken in clinical practice.

The choice of therapy and time and frequency of visits were based on each patient's individual requirements. Each patient concluded the study either after seizure remission (i.e., no seizures for at least 12 consecutive months), when the assigned treatment failed (i.e., it was withdrawn for any medical reason, which included inadequate seizure control and/or unbearable adverse events requiring modification other than dose adjustment), or after 18 months, whichever time point was reached first.
At admission, patients (or, where indicated, their caregivers) were interviewed for the collection of demographics and clinical data (date of first seizure, date of diagnosis, seizure type(s) [12], etiology, epileptic syndrome [13], comorbidities, concurrent nonantiepileptic treatments). Details of the first monotherapy (drug, daily dose, and any adverse events) were collected in ad hoc semistructured forms, with the reason(s) for changing treatment (i.e., efficacy and/or tolerability) and the new treatment choice. The new treatment was also recorded, with details on the AED, daily dose, and schedule of tapering. Each adverse event was coded according to the MedDra dictionary [14]. Adverse events were coded as either prevalent (present at study entry) or incident (occurring during follow-up). Any laboratory or instrumental investigation deemed necessary by the physician was also recorded and coded as an adverse event if abnormal.

At study entry, the QOLIE-31 inventory (a validated measure of HRQOL) [15] was administered to patients aged 18 years or older. At each subsequent visit, a follow-up form was completed by the physician, recording information regarding the interval from the previous visit. The form included the reason of the visit, a record of any recurrent seizure, adverse event, and action taken since the previous visit (laboratory tests, EEG tracings, imaging records, hospital admissions, outpatient visits, and treatment changes, with reasons and details). An "End-ofStudy" form was used at the close of the study or when a patient withdrew from the assigned treatment strategy, if that came first. Reasons for withdrawal were recorded. Between visits, patients (or their caregivers) reported details of seizures, adverse events, and medical resource consumption on ad hoc daily diaries. The physician examined the information in the diaries at follow-up visit and checked it for quality/ completeness. For those with incomplete or missing information in the diaries, data on seizure recurrence, adverse events, hospitalizations, outpatient consultations, and days off work/off school were collected at the time of the visit. At the end of follow-up, the QOLIE-31 was administered again.

The main endpoints included choice of treatment strategy (alternative monotherapy or add-on therapy) and, for each strategy, retention time (i.e., time elapsed from the start to the end of the study or to treatment discontinuation), seizure remission, treatment failure for recurring seizures, treatment failure for adverse events, medical resources consumed (hospital admissions and outpatient consultations), prevalence and incidence of adverse events, number of cases reporting days off work/off school, and QOLIE-31 total scores.

All the data recorded were entered into a standard computerized database. Data analysis included descriptive statistics and univariate and multivariate inferential analyses comparing alternative monotherapy and add-on therapy, in general and for children and adults separately. The statistical analysis plan included descriptive statistics of all the demographic and clinical variables of the sample at entry by treatment strategy, with details on AED schedules (with any changes) and adverse events at baseline and during follow-up, survival analysis for retention time (using Kaplan-Meier curves and log-rank test for comparisons), and multivariate analysis (using Cox's proportional hazard model, adjusting for age, center, epileptic syndrome, comorbidities, concurrent nonantiepileptic drugs, and other variables significant at univariate analysis). Statistical significance was also tested using the chi-square test for treatment failure, in general and separately for recurring seizures and adverse events and for seizure remission. Multivariate analysis was also used (for treatment failure and seizure remission separately) with a logistic regression model, adjusting for age, center, epileptic syndrome, comorbidities, concurrent nonantiepileptic drugs, and other variables significant at univariate analysis.

Finally, the Student's t-test, the Mann-Whitney test, and repeated measures analysis of variance (ANOVA) were used, as appropriate, for adverse events (in general and by severity, attribution to treatment, and outcome), the cumulative number of days off work/off school, and the QOLIE-31 scores, depending on the distribution of the data. 
Since this was an observational study, no formal sample size calculation was required. A total of 500 children and adults were originally planned to be included. During the course of the study, the recruitment rate was slower than expected. For this reason, considering the time of enlistment, the minimum number was reduced to 300 patients.

The study was approved by the institutional review board at each participating center.

\section{Results}

A total of 331 eligible patients from 58 centers were enrolled from October 2005 through December 2006. The sample comprised 157 males (47.4\%) and 174 females (52.6\%) aged 2 to 86 years (mean: 30.9, standard deviation (SD): 21.8). Table 1 lists the general characteristics of the sample. There were 124 children aged less than 18 years and 207 adults. The mean disease duration since seizure onset was 68.5 months (SD: 96.4) with symptoms lasting for more than 24 months in more than half of the cases (median: 29.4 months). Just over a third of the patients had a documented etiology of their seizures. Among symptomatic epilepsies, brain tumors, cerebrovascular disorders, structural malformations, and trauma were the commonest underlying epileptogenic disorders. Valproate was the commonest drug at baseline followed by carbamazepine, phenobarbital, and oxcarbazepine.

Two hundred and thirty-nine patients were switched to an alternative monotherapy and 92 received an add-on treatment. The two groups differed in time since seizure onset (mean [SD]: 63.3 [88.9] months for alternative monotherapy and 81.8 [113.0] months for addon therapy; $\mathrm{p}<0.01$ ), number of seizure types, epilepsy syndromes, and concomitant disorders (see Table 1 ). The commonest comorbidities included arterial hypertension and cardiovascular disorders (42 cases), diabetes and other endocrine/metabolic disorders (23 cases), congenital or developmental abnormalities (16 cases), and mental retardation (14 cases). Compared to alternative monotherapy, patients receiving add-on treatment had longer disease, more than one seizure type, partial seizures, focal epilepsy, and lack of comorbidity. The median number of seizures (with interquartile range) in the three months preceding enrolment was $3(0-10)$ in patients assigned alternative monotherapy and $2(1-4)$ in those assigned add-on therapy.

In the overall population, the initial monotherapy had to be changed mainly because of the lack of efficacy ( 243 cases) followed by adverse events ( 86 cases). In two cases, the change was required because of the need to use an AED with effects on mood in one and in the other for lack of effect and intolerable adverse events of monotherapy.

Treatment was discontinued because of adverse events more frequently in adults $(33.7 \%)$ than in children $(13.7 \%)(p<0.0001)$. In patients switched to an alternative monotherapy, the explanations were, in decreasing order, better tolerability ( 143 cases, $59.8 \%$ ), greater efficacy (63 cases, 26.4\%), better tolerability and greater efficacy (17 cases, $7.1 \%$ ), switch to a compound better suited to the individual case (10 cases, $4.2 \%$ ), greater ease of use (5 cases, $2.1 \%$ ), and patient's request ( 1 case, $0.4 \%$ ). Explanations did not differ for children and adults (data not shown). In all patients receiving add-on therapy, the caring physician expected greater efficacy with the addition of a second drug than with an alternative monotherapy.

Drugs assigned as alternative monotherapy differed from those given as add-on therapy (Table 2). In patients switched to alternative monotherapy, topiramate was the commonest drug, followed by carbamazepine, valproate, and oxcarbazepine. In patients receiving add-on therapy, topiramate prevailed, followed by levetiracetam, valproate, and carbamazepine. Significant differences in daily doses were seen with lamotrigine and levetiracetam when given as monotherapy (see Table 2).

Two hundred and forty-three patients (73.4\%) completed the study. Of these, 175 (52.9\%) had 12-month seizure remission. The cumulative
Table 1

General characteristics of the sample.

\begin{tabular}{|c|c|c|c|}
\hline Variable & $\begin{array}{l}\text { Total } \\
\text { No. (\%) }\end{array}$ & $\begin{array}{l}\text { Alternative } \\
\text { monotherapy } \\
\text { No. (\%) }\end{array}$ & $\begin{array}{l}\text { Add-on } \\
\text { therapy } \\
\text { No. (\%) }\end{array}$ \\
\hline \multicolumn{4}{|l|}{ Sex } \\
\hline Male & $174(52.6)$ & $130(54.4)$ & $44(47.8)$ \\
\hline Female & $157(47.4)$ & $109(45.6)$ & $48(52.2)$ \\
\hline \multicolumn{4}{|l|}{ Age (years) } \\
\hline$<18$ & $124(37.5)$ & $87(36.4)$ & $37(40.2)$ \\
\hline$>18$ & $207(62.5)$ & $152(63.6)$ & $55(57.8)$ \\
\hline \multicolumn{4}{|l|}{ Disease duration (months) ${ }^{* * *}$} \\
\hline$<12$ & 99 (29.9) & $83(34.7)$ & $16(17.4)$ \\
\hline $13-24$ & $48(14.5)$ & $31(13.0)$ & $17(18.5)$ \\
\hline$>24$ & $184(55.6)$ & $125(52.3)$ & $59(64.1)$ \\
\hline \multicolumn{4}{|l|}{ No. of seizure types* } \\
\hline 1 & $233(71.9)$ & $174(75.0)$ & $59(64.1)$ \\
\hline $2+$ & $91(28.1)$ & $58(25.0)$ & $33(35.9)$ \\
\hline NS & 7 & 7 & \\
\hline \multicolumn{4}{|l|}{ Seizure types } \\
\hline Partial $^{\mathrm{a}}$ & $229(66.2)$ & $156(62.9)$ & $73(74.5)$ \\
\hline Generalized & $112(32.4)$ & $88(35.5)$ & $29(24.5)$ \\
\hline Other & $5(1.4)$ & $4(1.6)$ & $1(1.0)$ \\
\hline \multicolumn{4}{|l|}{ Documented etiology } \\
\hline No & $206(62.5)$ & $149(62.3)$ & $57(63.0)$ \\
\hline Yes & $125(37.5)$ & $90(37.7)$ & $35(37.0)$ \\
\hline Neoplastic & $23(18.4)$ & $15(16.5)$ & $8(23.5)$ \\
\hline Cerebrovascular & $20(16.0)$ & $16(17.6)$ & $4(11.8)$ \\
\hline Structural malformation & $18(14.4)$ & $14(15.4)$ & $4(11.8)$ \\
\hline Trauma & $15(12.0)$ & $9(9.9)$ & $6(17.7)$ \\
\hline Degenerative & $9(7.2)$ & $7(7.7)$ & $2(5.9)$ \\
\hline Perinatal encephalopathy & $7(5.6)$ & $1(1.1)$ & $6(17.7)$ \\
\hline Infection & $4(3.2)$ & $4(4.4)$ & 0 \\
\hline Metabolic & $2(1.6)$ & $1(1.1)$ & $1(2.9)$ \\
\hline NS & $27(21.6)$ & $24(26.4)$ & $3(8.8)$ \\
\hline \multicolumn{4}{|l|}{ Epilepsy syndrome ${ }^{* *}$} \\
\hline Focal & $211(63.9)$ & $141(59.0)$ & $70(76.9)$ \\
\hline Generalized & $97(25.4)$ & $80(33.6)$ & $17(18.7)$ \\
\hline Undetermined & $16(4.9)$ & $14(5.8)$ & $2(2.2)$ \\
\hline Special & $6(1.8)$ & $4(1.8)$ & $2(2.2)$ \\
\hline NS & 1 & & 1 \\
\hline \multicolumn{4}{|l|}{ Concomitant disorders ${ }^{* *}$} \\
\hline No & $229(69.2)$ & $156(65.3)$ & $73(79.4)$ \\
\hline Yes & $102(30.8)$ & $83(34.7)$ & $19(20.6)$ \\
\hline Monotherapy at baseline & $108(32.6)$ & $75(31.4)$ & $33(35.9)$ \\
\hline Valproate & $49(14.8)$ & $30(12.6)$ & 19 (20.7) \\
\hline Carbamazepine & $44(13.3)$ & $38(15.9)$ & $6(6.6)$ \\
\hline Phenobarbital & $31(9.4)$ & $20(8.4)$ & $11(12.0)$ \\
\hline Topiramate & $21(6.3)$ & $19(8.0)$ & $2(2.2)$ \\
\hline Phenytoin & $20(6.0)$ & $15(6.3)$ & $5(5.4)$ \\
\hline Lamotrigine & $10(3.0)$ & $8(3.4)$ & $2(2.2)$ \\
\hline Levetiracetam & $8(2.4)$ & $8(3.2)$ & 0 \\
\hline Other ${ }^{\mathrm{b}}$ & & & \\
\hline \multicolumn{4}{|l|}{ Other drugs (non-AEDs) } \\
\hline No & $251(75.5)$ & $174(72.8)$ & $76(82.6)$ \\
\hline Yes & $81(24.5)$ & $65(27.2)$ & $16(17.4)$ \\
\hline
\end{tabular}

NS, not specified.

AEDs, antiepileptic drugs.

$* \mathrm{p}<0.05$.

$* * \mathrm{p}<0.02$

$* * * \mathrm{p}<0.01$.

a Include secondarily generalized seizures.

b Clobazam (2), clonazepam (1), diazepam (1), ethosuximide (2), gabapentin (1), and sulthiame (1).

time-dependent probability of remaining in the study was similar in patients switched to alternative monotherapy and those receiving add-on therapy (Fig. 1). Treatment failure was documented in 65 patients $(27.2 \%)$ on monotherapy and $23(25.0 \%)$ receiving two AEDs $(\mathrm{p}=\mathrm{ns})$. The main reasons were lack of efficacy (monotherapy: 21 cases, 32.3\%; add-on therapy: 11 cases, $47.8 \%$ ) and adverse events (monotherapy: 19 cases, 29.2\%; add-on therapy: 6 cases, 26.1\%) $(\mathrm{p}=\mathrm{ns})$. The mean retention time was 454.4 days (SD: 11.1$)$ for alternative monotherapy and 447.4 days (SD: 16.4 ) for add-on therapy. Mean retention times were longer in adults than in children ( 468.5 vs. 367.4 days, $\mathrm{p}=0.08$ ) but similar when comparing alternative 
Table 2

Details on substituted/added AED and highest dose (mg/day) during follow-up by treatment arm.

\begin{tabular}{|c|c|c|c|c|c|c|}
\hline & \multirow{2}{*}{\multicolumn{2}{|c|}{$\begin{array}{l}\text { Alternative } \\
\text { monotherapy } \\
(\mathrm{n}=239) \\
\text { Introduced drug }\end{array}$}} & \multicolumn{4}{|c|}{$\begin{array}{l}\text { Add-on therapy } \\
(\mathrm{n}=92)\end{array}$} \\
\hline & & & \multicolumn{2}{|c|}{ Added drug } & \multicolumn{2}{|c|}{ Pre-existing drug } \\
\hline & $\mathrm{n}$ & (mg/day) & $\mathrm{n}$ & (mg/day) & $\mathrm{n}$ & (mg/day) \\
\hline Barbexaclone & 0 & & 3 & 150.0 & 1 & 200.0 \\
\hline Carbamazepine & 32 & 783.1 & 7 & 857.1 & 19 & 1036.8 \\
\hline Clobazam & 1 & 20.0 & 2 & 20.0 & 0 & \\
\hline Clonazepam & 0 & & 1 & 0.5 & 0 & \\
\hline Ethosuximide & 2 & 400.0 & 5 & 510.0 & 0 & \\
\hline Phenytoin & 2 & 375.0 & 1 & 400.0 & 2 & 325.0 \\
\hline Phenobarbital & 1 & 100.0 & 6 & 100.0 & 5 & 125.0 \\
\hline Pregabalin & 1 & 300.0 & 5 & 330.0 & 0 & \\
\hline Lamotrigine* & 23 & 208.5 & 6 & 129.2 & 5 & 300.0 \\
\hline Levetiracetam $^{* *}$ & 21 & 1904.8 & 21 & 1404.8 & 2 & 2000.0 \\
\hline Oxcarbazepine & 29 & 1044.8 & 4 & 975.0 & 14 & 1478.6 \\
\hline Topiramate & 95 & 181.3 & 23 & 181.5 & 11 & 272.7 \\
\hline Valproate & 32 & 793.8 & 8 & 818.7 & 33 & 909.1 \\
\hline
\end{tabular}

* $\mathrm{p}<0.05$.

$* * \mathrm{p}<0.02$.

monotherapy and add-on therapy in children and adults separately (data not shown). The risk of leaving the study was higher for children than for adults (hazard ratio (HR): $2.2 ; 95 \% \mathrm{CI}$ : 1.1-4.4) and decreased progressively with age (HR: 0.99 for each additional year; $p<0.05$ ). Of the 239 patients switched to alternative monotherapy, 128 (53.6\%) achieved 12-month seizure remission. The corresponding figure for the 92 patients receiving add-on therapy was $47(51.1 \%)(\mathrm{p}=\mathrm{ns})$. The likelihood of remission by treatment strategy was no different for children and adults separately (data not shown).

A total of 129 prevalent adverse events (AEs) were reported by 94 patients (89 assigned subsequently to alternative monotherapy and five to add-on therapy) (Table 3). Adverse events were more frequent in adults than in children ( $36 \%$ vs. $15 \%$ ). The commonest events were nervous system disorders, followed by disorders of metabolism and
Table 3

Patients with adverse events present at study entry (MedDra categories) in the entire sample $(\mathrm{N}=331)$.

\begin{tabular}{lcl}
\hline Adverse event & N & $\%$ \\
\hline Blood and lymphatic system & 1 & $(0.3)$ \\
Endocrine & & \\
Gastrointestinal & 6 & $(1.8)$ \\
General and injection site & 4 & $(1.2)$ \\
Hepatobiliary & 1 & $(0.3)$ \\
Immune system & 1 & $(6.9)$ \\
Metabolism and nutrition & 23 & $(1.2)$ \\
Musculoskeletal and connective tissue & 4 & $(0.3)$ \\
Neoplasm & 1 & $(7.8)$ \\
Nervous system & 26 & $(2.4)$ \\
Psychiatric & 8 & $(1.2)$ \\
Renal and urinary & 4 & $(1.2)$ \\
Reproductive system and breast & 4 & $(3.9)$ \\
Skin and subcutaneous tissue & 13 & \\
\hline
\end{tabular}

nutrition and dermatological disorders (Table 3). Only 13 adverse events $(10.1 \%)$ were severe. In 86 patients, AEs were considered drug-related. During the study period, prevalent AEs resolved in the majority of patients (77\%).

Patients were followed for a total of 365.3 person-years. During this period, 383 incident AEs were reported by 148 patients, 111 on alternative monotherapy and 37 on add-on therapy (incidence ratio: 1.03 per patient/year; 95\% confidence interval (CI): 0.03-5.62). Adverse events were considered drug-related in 56 patients ( 45 on alternative monotherapy and 11 on add-on therapy). The incidence of AEs was 1.15 (95\% CI: 0.04-5.83) with alternative monotherapy and 0.75 (95\% CI: 0.00-5.13) with add-on therapy.

Nervous system disorders were the commonest complaints with a slight (nonsignificant) predominance in patients receiving alternative monotherapy, followed by gastrointestinal disorders, infections, psychiatric disorders, and respiratory disorders (Table 4). Adverse events with the highest cumulative incidence rate (i.e., between 1 and 2.3\%) were associated with the use of phenobarbital (including barbesaclone), clobazam, valproate, topiramate, and levetiracetam as

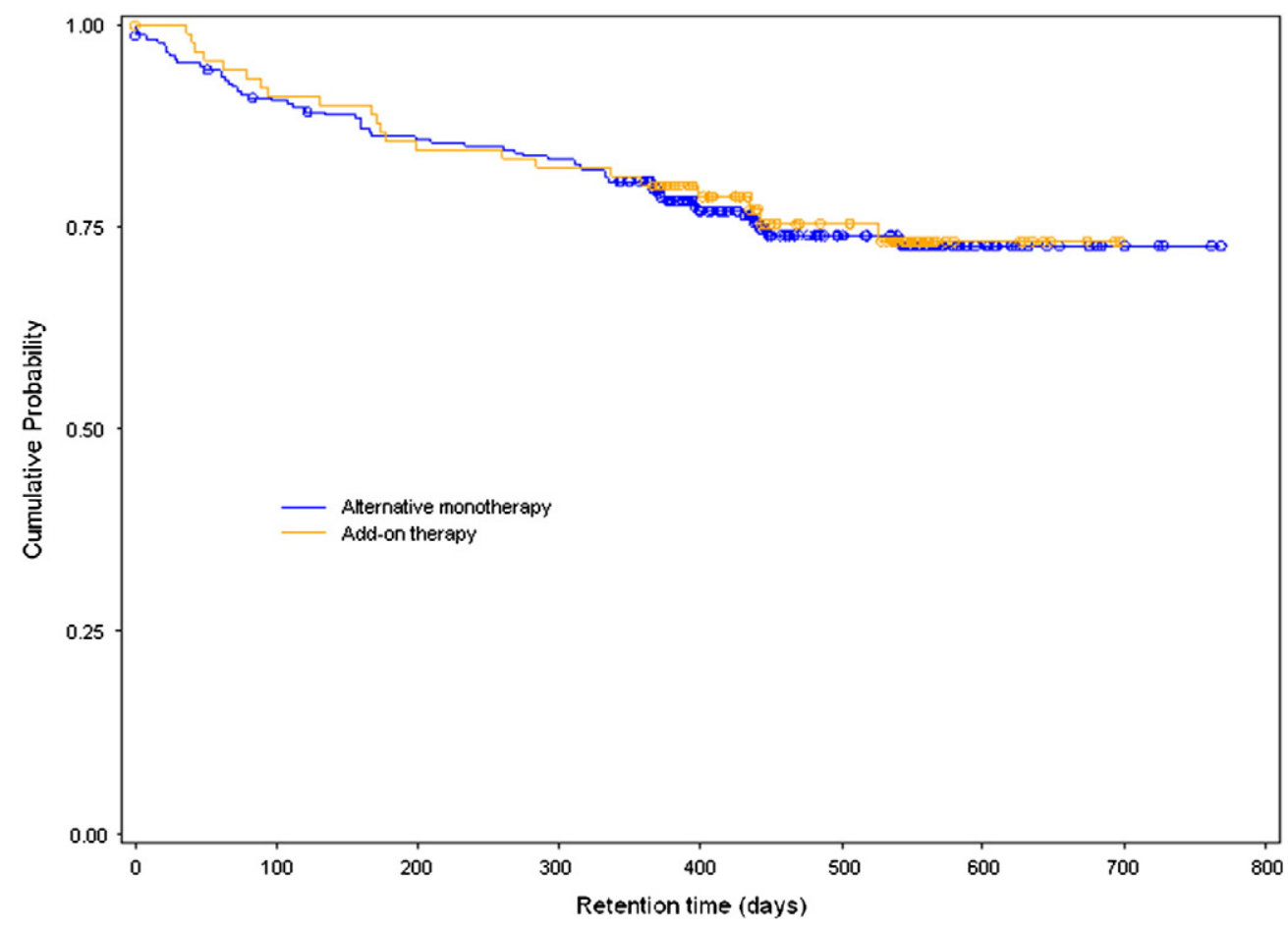

Fig. 1. Cumulative time-dependent probability of remaining in the study by treatment strategy. 
Table 4

Patients with adverse events occurring after study entry (MedDra categories) with relation to assigned treatment.

\begin{tabular}{|c|c|c|c|c|c|c|}
\hline \multirow[t]{2}{*}{ Adverse event } & \multicolumn{2}{|c|}{$\begin{array}{l}\text { Total } \\
(326)\end{array}$} & \multicolumn{2}{|c|}{$\begin{array}{l}\text { Alternative monotherapy } \\
\text { (235) }\end{array}$} & \multicolumn{2}{|c|}{$\begin{array}{l}\text { Add-on therapy } \\
\text { (91) }\end{array}$} \\
\hline & No. & $\%$ & No. & $\%$ & No. & $\%$ \\
\hline Blood and lymphatic system & 1 & 0.3 & 1 & 0.4 & - & - \\
\hline Cardiac & 3 & 0.9 & 2 & 0.9 & 1 & 1.1 \\
\hline Ear and labyrinth & 9 & 2.8 & 8 & 3.4 & 1 & 1.1 \\
\hline Eye & 1 & 0.3 & - & - & 1 & 1.1 \\
\hline Gastrointestinal & 30 & 9.2 & 26 & 11.1 & 4 & 4.4 \\
\hline General and injection site & 21 & 6.4 & 17 & 7.2 & 4 & 4.4 \\
\hline Hepatobiliary & 1 & 0.3 & 1 & 0.4 & - & - \\
\hline Immune system & 3 & 0.9 & 3 & 1.3 & - & - \\
\hline Infection and infestation & 22 & 6.7 & 14 & 6.0 & 8 & 8.8 \\
\hline Injury, poisoning, and procedural complication & 10 & 3.1 & 7 & 3.0 & 3 & 3.3 \\
\hline Investigations & 4 & 1.2 & 3 & 1.3 & 1 & 1.1 \\
\hline Metabolism and nutrition & 16 & 4.9 & 13 & 5.5 & 3 & 3.3 \\
\hline Musculoskeletal and connective tissue & 1 & 0.3 & - & - & 1 & 1.1 \\
\hline Neoplasm & 2 & 0.6 & 2 & 0.9 & - & - \\
\hline Nervous system & 61 & 18.7 & 49 & 20.9 & 12 & 13.2 \\
\hline Psychiatric & 26 & 8.0 & 19 & 8.1 & 7 & 7.7 \\
\hline Renal and urinary & 7 & 2.1 & 3 & 1.3 & 4 & 4.4 \\
\hline Reproductive system and breast & 5 & 1.5 & 5 & 2.1 & - & - \\
\hline Respiratory, thoracic, and mediastinal disorders & 24 & 7.4 & 18 & 7.7 & 6 & 6.6 \\
\hline Skin and subcutaneous tissue & 11 & 3.4 & 8 & 3.4 & 3 & 3.3 \\
\hline Surgical and medical procedures & 9 & 2.8 & 5 & 2.1 & 4 & 4.4 \\
\hline Vascular & 5 & 1.5 & 4 & 1.7 & 1 & 1.1 \\
\hline
\end{tabular}

AED, antiepileptic drug. None of the differences are statistically significant.

either monotherapy or add-on therapy, but in most cases, they were considered to be unrelated to the medication. Most incident AEs subsided during follow-up. A total of 30 patients (22 on alternative monotherapy and 8 on add-on therapy) reported 37 serious adverse events (28 in monotherapy and 9 in add-on therapy; 20 in adults and 17 in children), which, in most cases, were not drug-related. Serious adverse events resolved in 35 instances and ended in death in two. These two patients had symptomatic epilepsy caused, in one, by congenital hydrocephalus and, in the other, by a brain tumor. Severity and outcome were no different in patients on alternative monotherapy or add-on therapy.

A total of 160 patients (48.3\%) completed the diaries; 28 (8.5\% of the entire sample) were hospitalized during the study. The median (range) hospital stay was six days (1-25), was similar with alternative monotherapy (median: 5; range: 1-25) and polytherapy (median: 6; range: $3-19$ ), and was different for children and adults only for polytherapy (median: 18 and 3 days). Seventeen patients (5.1\%) needed one or more day-hospital admissions. The median (range) number of day-hospital admissions was 2 (1-15) and was slightly different for patients on alternative monotherapy and those on polytherapy (median: 3 and 1.5 ). Forty-three patients (13.0\%) had outpatient consultations. The median (range) number of consultations was 1 (1-6) and did not differ with treatment strategy and age (data not shown). Twenty-two patients (10.6\%) lost a total of 438 work-days and 41 (33.1\%) a total of 691 school-days during the study. The likelihood of missing work or school was not affected by treatment strategy or age.

One hundred adult patients on alternative monotherapy and 23 on add-on therapy filled the QOLIE-31 inventory at baseline and at study end. Their mean total scores were 58.9 and 57.7 at baseline and 61.9 and 60.7 at study end, respectively. However, repeated measures ANOVA showed within-subject differences for the domains Seizure worry, and Overall quality of life with no interaction between treatment and time (Table 5).

\section{Discussion}

In this study, $72.2 \%$ of children and adults with epilepsy seen in secondary and tertiary centers in whom a first monotherapy had failed were switched to an alternative monotherapy, and a second drug was added to the current treatment in only $27.8 \%$. This prevailing strategy can be explained by the merits of monotherapy, which have been widely demonstrated [16], and is in keeping with the therapeutic habits in other Mediterranean countries [7], with the recommendations in evidence-based guidelines [17-19] and with the

Table 5

QOLIE-31 scores $^{\mathrm{a}}$ in patients on alternative monotherapy and add-on therapy $(\mathrm{N}=123)$.

\begin{tabular}{|c|c|c|c|c|c|c|c|}
\hline \multirow[t]{2}{*}{ Domain } & \multicolumn{2}{|l|}{ Basal score } & \multicolumn{2}{|l|}{ Final score } & \multirow{2}{*}{$\begin{array}{l}\text { Therapy effect } \\
\text { (between subjects) } \\
\text { p value }\end{array}$} & \multirow{2}{*}{$\begin{array}{l}\text { Time effect } \\
\text { (within subjects) } \\
\text { p value }\end{array}$} & \multirow[t]{2}{*}{ Therapy $\times$ time } \\
\hline & $\begin{array}{l}\text { Monotherapy } \\
\text { Mean }(95 \% \text { CI })\end{array}$ & $\begin{array}{l}\text { Add-on therapy } \\
\text { Mean }(95 \% \mathrm{CI})\end{array}$ & $\begin{array}{l}\text { Monotherapy } \\
\text { Mean }(95 \% \mathrm{CI})\end{array}$ & $\begin{array}{l}\text { Add-on therapy } \\
\text { Mean }(95 \% \mathrm{CI})\end{array}$ & & & \\
\hline Social functioning & $64.1(59.2 ; 69.0)$ & $60.0(49.4 ; 70.5)$ & $66.4(61.8 ; 70.9)$ & $62.8(52.9 ; 72.9)$ & 0.44 & 0.281 & 0.91 \\
\hline Medication effects & $47.8(42.0 ; 53.6)$ & $55.8(44.9 ; 66.7)$ & $54.1(47.8 ; 59.6)$ & $59.5(47.2 ; 71.9)$ & 0.25 & 0.11 & 0.63 \\
\hline Cognitive & $64.2(59.5 ; 68.9)$ & $62.6(51.0 ; 74.2)$ & $64.0(59.6 ; 68.3)$ & $62.1(53.0 ; 71.2)$ & 0.72 & 0.88 & 0.96 \\
\hline Energy fatigue & $49.3(45.6 ; 53.0)$ & $53.7(45.6 ; 61.8)$ & $54.6(51.0 ; 52.8)$ & $55.9(62.9 ; 49.0)$ & 0.44 & 0.06 & 0.45 \\
\hline Emotional well-being & $57.0(53.3 ; 60.7)$ & $61.6(53.1 ; 70.1)$ & $59.4(56.0 ; 62.8)$ & $63.1(55.3 ; 71.0)$ & 0.26 & 0.34 & 0.84 \\
\hline Overall quality of life & $59.5(56.3 ; 62.6)$ & $55.5(47.5 ; 63.6)$ & $64.2(61.2 ; 67.2)$ & $62.3(55.1 ; 69.5)$ & 0.35 & $<0.01$ & 0.62 \\
\hline Seizure worry & $49.7(44.2 ; 55.2)$ & $38.6(29.1 ; 48.0)$ & $57.9(52.9 ; 62.8)$ & $50.1(41.0 ; 59.3)$ & 0.08 & $<0.01$ & 0.51 \\
\hline Total score & $58.9(55.5 ; 62.3)$ & $57.7(46.8 ; 65.6)$ & $61.9(58.7 ; 65.1)$ & $60.7(54.2 ; 67.1)$ & 0.73 & 0.07 & 1.00 \\
\hline
\end{tabular}

The column "Therapy effect" indicates the level of significance of the difference between the two treatment strategies. The column "Time effect" indicates the level of significance of the difference between baseline and the end of study (both treatments combined). The column "Therapy $\times$ time effect" indicates the interaction between treatment strategy and time.

$\mathrm{CI}=$ confidence interval.

a A higher score indicates a better quality of life, in total and for each domain separately. 
opinions of US epilepsy experts [8]. Advocates of monotherapy claim a lower incidence of adverse events, less potential for drug interaction, better compliance, and reduced costs. Our data do not support these claims because the direct, indirect, and intangible costs (measured respectively by the number of consultations and hospital admissions, the number of work or school absences, and the HRQOL scores) were similar in the two treatment groups, and the overall incidence of adverse events was slightly lower in patients receiving a combination therapy. In addition, the adverse events reported by the two treatment cohorts were similar as regards severity, attribution to drug, and outcome.

These findings are in keeping with randomized trials comparing mono- and polytherapy, which showed a lower cumulative number of adverse effects in patients on polytherapy [6] and fewer polytherapy patients withdrawing from the study because of adverse effects [20]. This slight (nonsignificant) difference cannot be explained by the lower target daily doses in patients receiving add-on therapy than those switched to alternative monotherapy, as this was true only for lamotrigine and oxcarbazepine, two drugs for which the incidence ratio of adverse events was among the lowest. One possible explanation is the absence of cumulative (adverse) effects of antiepileptic drugs when given in combination. An alternative explanation is the prevalence of concomitant disorders, which was higher in patients switched to alternative monotherapy (34.7\%) than in those receiving add-on therapy (20.6\%).

Valproate was the commonest drug at study entry, followed by carbamazepine, phenobarbital, and oxcarbazepine. Topiramate was the commonest drug given as alternative monotherapy, followed by carbamazepine, valproate, and oxcarbazepine. Topiramate was also preferred for add-on therapy, followed by levetiracetam. Minor differences were seen between children and adults. The physicians' attitude emerging in this study shows that after failure of a first monotherapy, a secondgeneration AED is more likely to be chosen. Drug choice perhaps reflects each physician's experience with each compound and the different spectra of approved indications for each AED at the time of study entry.

The incidence of adverse events was higher in children than in adults and varied across drugs, with phenobarbital and clobazam at one extreme and ethosuximide at the other. Differences did not attain statistical significance, however, possibly because of the small numbers within subgroups.

Retention time and 12-month chance of seizure remission were similar in the two groups. Even with differences in remission rates compared to other reports [5,6,20], our findings confirm the results of randomized trials $[6,20]$ and suggest that when a first monotherapy fails, the probability of subsequent success is largely independent of treatment strategy.

Interestingly, children had a lower retention time than adults, irrespective of treatment strategy. This might be explained by the greater alarm evoked in parents/caregivers by a lack of effect or poor tolerability of treatment.

The study has some strengths and several limitations. The major strength is the sample size. Other observational studies which assessed the effects of substitution therapy and add-on therapy were done in small series of patients [5]. A second strength is the nationwide distribution of the participating centers which, to some extent, represent current clinical management of epilepsy in Italy. A third strength is the prospective study design, with predefined assessment and control of all the study variables.

The main shortcomings of this study include the nonrandomized nature of the design, the uncontrolled drug choice, and the lack of blinding procedures, which prevent comparisons across drugs and drug combinations. However, this was a pragmatic, prospective, observational investigation and, as such, treatment choice and (adverse) effects were reported with knowledge of the underlying treatment and in line with clinical practice in Italy. Another probably relevant limitation is the sample size, which may have been too small to detect differences in light of the different proportions of patients assigned to monotherapy and add-on therapy. In addition, outcome measures like number of cases admitted to hospital or outpatient consultations and absence from work or school were so infrequent as to prevent detection of even a major difference. By the same token, the number of patients interviewed for the assessment of quality of life was perhaps too small to detect differences in the scores. Then, it is to be assumed that the participating investigators used their clinical judgment to determine the best therapeutic approach (add-on vs. switch) for each individual patient, thus ensuring a beneficial treatment outcome. Because of individualization of the treatment and trial-related lack of randomization, a true interpretation of the risk and benefits of both treatment approaches cannot be derived from this study.

In conclusion, the preferred use of alternative monotherapy when the first treatment fails does not necessarily lead to a better outcome, in terms of seizure recurrence and adverse treatment effects. Alternative monotherapy should be weighed against polytherapy in terms of expected efficacy, tolerability, and costs for each individual patient.

\section{Conflict of interest}

Dr. Millul has received personal compensation for consultancy by Novartis Vaccines. Dr. Iudice has received personal compensation for consultancy by Janssen-Cilag. Drs. Adami and Porzio are employees of Janssen-Cilag. Dr. Mattana has no conflicts of interest. Dr. Beghi serves on the editorial advisory boards of Epilepsia, Amyotrophic Lateral Sclerosis, Clinical Neurology \& Neurosurgery, and Neuroepidemiology; has received money for board membership by VIROPHARMA and EISAI; has received funding for travel and speaker honoraria from UCB-Pharma, Sanofi-Aventis, GSK; and has received funding for educational presentations from GSK.

\section{Ethical publication}

We confirm that we have read the Journal's position on issues involved in ethical publication and affirm that this report is consistent with those guidelines.

\section{Acknowledgments and funding}

The study was sponsored by Janssen-Cilag SpA.

\section{References}

[1] Annegers JF, Hauser WA, Elveback LR. Remission of seizures and relapse in patients with epilepsy. Epilepsia 1979;20:729-37.

[2] Cockerell OC, Johnson AL, Sander JW, Hart YM, Shorvon SD. Remission of epilepsy: results from the National General Practice Study of Epilepsy. Lancet 1995;346:140-4.

[3] Collaborative Group for the Study of Epilepsy. Prognosis of epilepsy in newly referred patients: a multicenter prospective study of the effects of monotherapy on the long-term course of epilepsy. Epilepsia 1992;33:45-51.

[4] Kwan P, Brodie MJ. Early identification of refractory epilepsy. N Engl J Med 2000;342:314-9.

[5] Deckers CLP, Genton P, Sills GJ, Schmidt D. Current limitations of antiepileptic drug therapy: a conference review. Epilepsy Res 2003;53:1-17.

[6] Beghi E, Gatti G, Tonini C, ben-Menachem E, Chadwick DW, Nikanorova M, et al. Adjunctive therapy versus alternative monotherapy in patients with partial epilepsy failing on a single drug: a multicentre, randomized, pragmatic controlled trial. Epilepsy Res 2003;57:1-13.

[7] Baldy-Moulinier M, Covanis A, D'Urso S, Eskazan E, Fattore C, Gatti G, et al. Therapeutic strategies against epilepsy in Mediterranean countries: a report from an international collaborative survey. Seizure 1998;7:513-20.

[8] Karceski S, Morrell MJ, Carpenter D. Treatment of epilepsy in adults: expert opinion, 2005. Epilepsy Behav 2005;7:S1-S64.

[9] Kwan P, Brodie MJ. Drug treatment of epilepsy: when does it fail and how to optimize its use? CNS Spectr 2004;9:110-9.

[10] Brodie MJ, Kwan P. Staged approach to epilepsy management. Neurology 2002;58(Suppl. 5):S2-8.

[11] Commission on Epidemiology and Prognosis, International League Against Epilepsy. Guidelines for epidemiologic studies on epilepsy. Epilepsia 1993;34:592-6.

[12] Commission on Classification and Terminology of the International League Against Epilepsy. Proposal for revised clinical and electroencephalographic classification of epileptic seizures. Epilepsia 1981;22:489-501. 
[13] Commission on Classification and Terminology of the International League Against Epilepsy. Proposal for revised classification of epilepsies and epileptic syndrome. Epilepsia 1989;30:389-99.

[14] Medical dictionary for regulatory activities. Version 14.0. Northrop Grumman Corporation; 2011.

[15] Beghi E, Niero M, Roncolato M. Validity and reliability of the Italian version of the Quality-of-Life in Epilepsy Inventory (QOLIE-31). Seizure 2005;14:452-8.

[16] Beghi E, Perucca E. The management of epilepsy in the 1990s: acquisitions, uncertainties, and perspectives for future research. Drugs 1995;49:680-94.
[17] National Institute for Clinical Excellence. Newer drugs for epilepsy in adults. www.nice.org.uk/Docref.asp?d=110081 [accessed Aug 31, 2004].

[18] National Institute for Clinical Excellence. Newer drugs for epilepsy in children. www.nice.org.uk/Docref.asp?d=113359 [accessed Aug 31, 2004].

[19] Scottish Intercollegiate Guidelines Network. Diagnosis and management of epilepsy. www.sign.ac.uk/pdf/sign70.pdf [accessed July 31, 2004].

[20] Deckers CLP, Hekster YA, Keyser A, van Lier HJJ, Meinardi H, Renier WO. Monotherapy versus polytherapy for epilepsy: a multicenter double-blind randomized study. Epilepsia 2001;42:1387-94. 